\title{
A ANALÍTICA QUEER E SEU ROMPIMENTO COM A CONCEPÇÃO BINÁRIA DE GÊNERO
}

\section{THE ANALYTICAL QUEER AND HIS BREAK WITH THE GENDER BINARY DESIGN}

\section{ELOISIO MOULIN DE SOUZA}

Doutor em Psicologia pelo Programa de Pós-Graduação em Psicologia pela

Universidade Federal do Espírito Santo (Ufes).

Professor adjunto do Departamento de Administração da Universidade Federal do Espírito Santo. Avenida Fernando Ferrari, 514, Goiabeiras - Vitória - ES - Brasil - CEP 29075-910 E-mail: eloisiomoulin@gmail.com

\section{ALEXANDRE DE PÁDUA CARRIERI}

Doutor em Administração pelo Centro de Pós-Graduação e Pesquisas em Administração da

Universidade Federal de Minas Gerais (UFMG). Professor adjunto Departamento de Administração da Universidade Federal de Minas Gerais. Avenida Antônio Carlos, 6.627, Pampulha - Belo Horizonte - MG - Brasil - CEP $31270-901$ E-mail: alexandre@cepead.face.ufmg.br 


\section{RESUMO}

A analítica queer comumente relacionada a estudos de gênero é uma abordagem conceitual recente. Este artigo objetiva principalmente trazer à tona essa perspectiva pouco explorada na análise crítica do campo organizacional. Os principais conceitos e princípios relacionados às ideias contidas no pensamento queer são apresentados, e discutem-se as principais diferenças entre a analítica queer e os estudos modernistas de gênero. A analítica queer está fundamentada em Foucault que defende uma visão pós-identitária e fragmentada em relação ao pensamento identitário/binário hegemônico sobre a sexualidade e os estudos de gênero. Tal visão é fundamental para o fomento de resistência e desenvolvimento de práticas organizacionais locais e empíricas que possam promover uma atuação e intervenção diante das práticas opressivas direcionadas não só à sexualidade, mas também a outras formas de opressão no local de trabalho. Conclui-se que a emancipação das práticas hegemônicas de poder contemporâneas reside na visão pós-identitária e não binária de mundo como possibilidade de contribuição para a construção de uma nova realidade social nas organizações, realidade esta que possa combater os dispositivos de biopoder relacionados não somente à sexualidade, mas também aos demais dispositivos de poder.

\section{PALAVRAS-CHAVE}

Analítica queer; Pós-estruturalismo; Relações sociais de sexo; Gênero; Foucault.

\section{ABSTRACT}

The Analytical Queer commonly related to gender studies is a recent conceptual approach. Thus, this article aims primarily to bring out this little explored perspective on the critical analysis of the organizational field. The main concepts and principles related to the ideas contained in queer thought are presented, and the main differences between the analytical queer studies and modernist 
studies about gender are discussed. The Analytical Queer is based on Foucault concepts about post-identity and fragmentation that substitutes the hegemonic thinking of identity/binary in sexuality and gender studies, this post-identity vision is essential for the development of resistance and development of organizational local practices and may promote an action and intervention in the face of oppressive practices directed not only sexuality but also to other forms of oppression in the workplace. We conclude that the emancipation of the hegemonic practice of contemporary power lies in the post-identity and non-binary world as a possible contribution to the construction of a new social reality in organizations, a reality which can combat the bio-power related devices not only about sexuality, but also to other power devices.

\section{KEYWORDS}

Analytical Queer; Post-structuralism; Social relations of sex; Gender; Foucault.

\section{INTRODUÇÃO}

Este artigo objetiva principalmente trazer à tona uma perspectiva crítica de análise pouco explorada nos estudos organizacionais brasileiros, conhecida como teoria queer (FOURNIER; GREY, 2007), ao mesmo tempo que se problematiza a utilização dos termos "teoria" e "gênero" sob essa perspectiva crítica de análise. Para tanto, realizou-se uma revisão bibliográfica sobre o tema, caracterizando este artigo como uma pesquisa qualitativa. Portanto, os principais conceitos e princípios relacionados às ideias contidas na teoria queer são apresentados, bem como as principais diferenças entre a teoria queer e os estudos modernistas de gênero.

Este trabalho difere-se dos outros relacionados à teoria queer desenvolvidos principalmente por Louro (2004, 2008), Lara Neto (2007), Miskolci (2007), De Lauretis (1987), Irigaray (2007a, 2007b, 2008) e Pino (2007), por entender que Foucault (1984, I985, I988, I999) não desenvolveu uma teoria, mas sim uma analítica sobre o poder, exatamente para fugir da construção de metanarrativas, presentes nos estudos estruturalistas. Assim, defende-se a substituição da denominação teoria queer por analítica queer. Além disso, pretende-se romper com o uso do termo gênero, substituindo-o pela expressão relações sociais de sexo. Desse modo, pretende-se enfatizar não apenas que masculino e feminino são construídos por relações de poder historicamente fundamentadas, mas também que essas categorias não são naturais e nem existem a priori. O conceito de relações sociais de sexo 
empregado pelos autores deste artigo tem o objetivo de denunciar e desconstruir a existência a priori dessas duas categorias por meio da problematização das relações de poder que atuam como dispositivos de controle sobre a sexualidade.

Vale ressaltar que existem diversas abordagens críticas utilizadas no campo organizacional. Fournier e Grey (2007) consideram, entre elas, os trabalhos neomarxistas, pós-estruturalistas, desconstrucionistas, críticos literários, feministas, psicanálistas, ambientalistas e estudos culturais. Os autores ainda consideram o pós-colonialismo e a teoria queer abordagens críticas desenvolvidas mais recentemente e que ainda não tiveram impacto sobre os estudos organizacionais. Contudo, apesar de todas essas abordagens serem denominadas e classificadas em uma mesma categoria, isso não significa que tenham a mesma base epistemológica e ontológica. Nesse sentido, destaca-se que a teoria queer está epistemologicamente fundamentada no pós-estruturalismo.

A teoria queer objetiva analisar a presença de uma visão pós-identitária, enxergando-se a fragmentação como uma possibilidade para um maior engajamento na construção de práticas organizacionais, localizadas e empíricas, que promovam atuação e intervenção diante de práticas opressivas direcionadas à sexualidade, por meio da análise de dispositivos de poder, principalmente os dispositivos da sexualidade e do trabalho.

O artigo iniciará com uma discussão sobre a emergência do modelo binário de sexualidade e as diversas definições sobre gênero. Em seguida, a analítica queer será apresentada, demonstrando o que a diferencia das perspectivas de análise de gênero anteriormente descritas.

\section{A REIFICAÇÃO DO BINÁRIO NOS ESTUDOS DE GÊNERO}

Para Laqueur (I996), a diferença de sexos surge nos séculos XVIII e XIX. Assim, influenciado pelo neoplatonismo, o Ocidente não concebia a sexualidade humana como algo binário e dividido entre masculino e feminino até o século XVIII. Desse modo, até o século XVIII, o modelo de sexualidade era o one-sex model. Supor que tenha existido outra forma de pensar a sexualidade, para nós, seres humanos construídos em um mundo onde a diferença de sexos é algo naturalizado e reforçado no nosso pensamento diário, não é nada fácil. Como sujeitos cultural e historicamente constituídos, passamos a vislumbrar a divisão entre masculino e feminino como algo fixo, natural, indiscutível e repleto de verdades inquestionáveis, ou seja, como algo reificado.

Sob o one-sex model, que prevaleceu no Ocidente durante aproximadamente vinte séculos, só existia um sexo. A mulher era vista como representante inferior 
de um único sexo que possuía hierarquia corporal. No topo dessa hierarquia, estava o corpo do homem considerado como grau máximo de perfeição; havia uma escala de perfeição que começava com a mulher e atingia seu apogeu com o homem. A mulher não era considerada algo diferente do homem, mas um homem invertido e inferior. Por dois milênios, por exemplo, o ovário de uma mulher não tinha nome próprio. O que denominamos hoje de ovário era chamado de testículos (testiculi). O clitóris, quando descoberto, foi denominado de pênis da fêmea. Assim, a presença de um pênis da fêmea, interno e externo, ambos sujeitos à ereção, prazer e ejaculação, não perturbava os escritores e pesquisadores dos séculos XVI e XVII, mas fornecia todo um registro para a ordenação hierárquica do sexo. Portanto, até o século XVIII, não havia problema algum em sustentar que as mulheres tinham uma inversão topológica do pênis do macho dentro delas e que possuíam os mesmos órgãos que os homens, funcionando da mesma maneira (LAQUEUR, I996). Costa (1995, p. 104) afirma que, nessa época,

[...] a diferença entre mulheres e homens era percebida; só não era explicada pela diferença de sexos. O que chamamos de sexo, hoje, era a palavra usada para designar apenas os órgãos reprodutores. Considerando as genitais, a mulher era, de fato, uma simples especialização funcional anatomicamente identificada como masculina em sua natureza. A forma cultural de distinguir os gêneros masculino e feminino dispensava o recurso à diferença dos sexos.

Conforme Costa (I995), a teoria da diferença sexual nasceu do interesse filosófico, moral e político de encontrar algo para justificar a inferioridade políticojurídico-moral da mulher. A mudança do parâmetro científico só ocorreu por causa da antecipação da polêmica cultural em torno da natureza e do papel da mulher na sociedade, e não em razão das novas descobertas científicas. A alteração da visão cultural

[...] sobre a mulher aconteceu muito antes de qualquer prova científica do dimorfismo sexual originário. Distinguir a mulher do homem pela particularidade do sexo foi uma preocupação de filósofos e moralistas do Iluminismo, antes de ser uma crença científica (COSTA, I995, p. I08).

A necessidade de diferenciar homens e mulheres era uma preocupação do pensamento iluminista que acabou influenciando a forma como as ciências conceberam e interpretaram as questões relacionadas ao sexo. Como, após o Iluminismo, as ciências passam a ocupar um lugar de destaque em nossa sociedade ocidental, a 
[...] influência da linguagem científica sobre a linguagem ordinária, a partir do século XIX, [...] é um fator do sucesso das ideologias sexuais. De fato, boa parte das idéias que mantemos sobre sexualidade, deve-se ao prestígio da ciência no imaginário cultural (COSTA, I995, p. IOI).

Assim, pode-se afirmar que,

[...] ao contrário do que se pensa habitualmente, não foi o estabelecimento da diferença dos sexos que condicionou o lugar social, moral e psicológico da mulher; foi a discussão de seu novo estatuto social que deu origem à diferença de sexos como a conhecemos. A formação da nova imagem da mulher nos séculos XVIII, e sobretudo XIX, trouxe à tona a rediscussão da diferença de gêneros. Desta rediscussão surgiu a idéia da diferença de sexos entendida como bissexualidade original e não como hierarquização de funções de um só sexo fisio-anatômico (COSTA, I995, p. 104).

Sob esse aspecto, a ciência não se apresenta como algo neutro, mas é investida e concebida em uma rede de poder. A vida, como objeto do poder, é um dos grandes fenômenos do século XIX e vem com o surgimento e a organização do Estado, que passa a ocupar o lugar das monarquias. Ocorre, nessa época, "uma tomada de poder sobre o homem enquanto ser vivo, uma espécie de estatização do biológico ou, pelo menos, certa inclinação que conduz ao que se poderia chamar de estatização do biológico" (FOUCAULT, I999, p. 286). Tal fenômeno é denominado por Foucault de biopoder, exercido em relação a determinada população. O biopoder não se preocupa com o indivíduo, mas lida com uma população que é um problema político, biológico, científico e, concomitantemente, um problema de poder. É em relação a fenômenos que aparecem com o surgimento de uma sociedade industrial que a biopolítica intervirá por meio de instituições de assistência como mecanismos sutis de seguros, de poupança individual e de seguridade, com o intuito de gerir a incapacidade dos indivíduos ao mesmo tempo que se constitui como uma forma de exclusão e de neutralização do indivíduo (FOUCAULT, I999).

A diferenciação biológica do sexo é um dos dispositivos do biopoder. Para Foucault (I988), o biopoder foi elemento indispensável para o desenvolvimento do capitalismo. O capitalismo só logrou sucesso e vida por meio do controle dos corpos no aparelho de produção e de uma regulamentação ou ajustamento dos fenômenos populacionais ao sistema econômico. Fez-se para o capitalismo necessário aumentar a utilidade e a docilidade dos corpos, as forças, as habilidades e a vida em geral sem tornar as pessoas mais difíceis de sujeitar. 
Os valores capitalistas exercem o poder para segregar e simultaneamente hierarquizar a sociedade, garantindo relações de dominação e provocando efeitos de hegemonia. A adaptação da acumulação dos homens à da acumulação do capital, "a articulação do crescimento dos grupos humanos à expansão das forças produtivas e a repartição diferencial do lucro, foram, em parte, tornados [sic] possíveis pelo exercício do biopoder com suas formas e procedimentos múltiplos" (FOUCAULT, I988, p. 133).

É dessa forma que fenômenos ligados à vida da espécie humana entram na área das técnicas políticas e passam a ser o objeto da relação poder-saber. A biopolítica "faz com que a vida e seus mecanismos entrem no domínio dos cálculos explícitos, e faz do poder-saber um agente de transformação da vida humana" (FOUCAULT, I988, p. I34).

Apoiando-se no conceito de dispositivo contido em Foucault (1984, I985, I988), Nardi (2007) afirma que, em nossa sociedade, existem dois dispositivos centrais - o trabalho e a sexualidade - que funcionam como organizadores da vida social e criadores de subjetividades. Para esse autor, por meio da biopolítica, somos chamados à responsabilidade e produção, ou melhor, somos corresponsáveis pela riqueza de uma nação e temos de nos reproduzir seguindo um modelo de família heterossexual monogâmica.

A bipolarização biológica do sexo, denominada por Laqueur (I996) de two-sex model, diferenciará o homem da mulher e vai justificar e criar diferenças morais aos comportamentos femininos e masculinos em função das necessidades e exigências da sociedade burguesa, capitalista, nacionalista e individualista (COSTA, I995). A "reinterpretação dos corpos humanos conforme o mito da bissexualidade original foi, antes de tudo, uma solução exigida pelos problemas políticoideológicos postos pela revolução burguesa" (COSTA, I995, p. III).

Para Foucault (I988), a sociedade que se desenvolve no século XVIII, denominada por ele de burguesa, capitalista ou industrial, não teve uma recusa em conhecer o sexo, pelo contrário, instaurou todo um aparelho capaz de produzir discursos verdadeiros sobre o sexo. Não apenas falou muito sobre ele, como também forçou todo o mundo a falar dele, além de formular uma verdade sobre ele

[...] como se suspeitasse nele um segredo capital. Como se tivesse necessidade dessa produção de verdade. Como se lhe fosse essencial que o sexo se inscrevesse não somente numa economia do prazer, mas, também, num regime ordenado de saber (FOUCAULT, I988, p. 68).

Ora, a relação poder-saber que emerge a partir do século XVIII vai ditar a lei no que diz respeito ao sexo. O sexo fica reduzido a um regime binário de lícito e ilícito, permitido e proibido (FOUCAULT, I988). 
A divisão das pessoas em homens e mulheres, homossexuais e heterossexuais, era algo teoricamente impossível e, em termos sociais, algo impraticável anteriormente à diferenciação dos sexos. Assim, ocorre a invenção dos homossexuais e heterossexuais como uma consequência político-teórica das normas feitas à mulher e ao homem no two-sex model (COSTA, 1995).

Tendo-se feito uma análise histórica da proveniência da divisão biológica do homem em dois sexos e, consequentemente, do surgimento dos estudos que envolvem gênero, resta esclarecer algumas questões: o que realmente significa gênero? Qual é o significado dessa palavra? Esse significado é fixo no tempo, ou seja, é a-histórico? Para responder a essas questões, o próximo tópico explicará os principais conceitos de gênero que emergiram com a concepção de uma sexualidade binária contida na modernidade.

\section{GÊNERO E SEUS SIGNIFICADOS HEGEMOONICOS}

Diante do exposto, fica claro que, somente a partir do século XVIII, é que podemos falar de gênero. Sob essa perspectiva, o significado de gênero é visto como construído historicamente de acordo com as relações sociais e de poder de uma época. Anteriormente, no one-sex model, só havia um sexo e não fazia o menor sentido discutir aspectos relacionados a gênero. Apesar de não podermos afirmar que existe um único conceito de gênero, podemos corroborar que, em sua visão científica mais tradicional, ele só passa a existir com a divisão do homem em dois sexos: masculino e feminino. Divisão esta que a ciência passa a incorporar como verdade inquestionável. Um exemplo de tal afirmação é a definição de gênero como algo ligado às relações sociais estabelecidas a partir do momento da percepção social das diferenças biológicas existentes entre os sexos. É apenas no two-sex model que ocorre uma divisão e horizontalidade dos sexos (masculino e feminino), que passam a ser vistos como opostos e incomensuráveis (HEIBORN, I998).

O principal intento disso reside na tentativa de tornar as diferenças de sexo algo natural e determinado. Como consequência, "a sexualidade passa a ser identificada a uma força instintiva, biológica e, assim, não merecia ser historicizada" (RAGO, I998. p. 30). Surge uma tríade que estará presente em boa parte dos estudos de gênero: sexo, gênero e sexualidade. Mas, além de ser uma tríade, existe uma relação de causa-efeito entre eles em que o sexo define o gênero e o gênero define a sexualidade das pessoas. A trilogia sexo-gênero-sexualidade será canonizada e servirá como definidora e reguladora de todo comportamento 
social relacionado à sexualidade. Em relação a essa santíssima trindade, Louro (2004, p. 65-66) afirma:

A premissa que afirma que determinado sexo indica determinado gênero e este gênero, por sua vez, indica ou induz o desejo. Nessa lógica, supõe-se que o sexo é "natural" e se entende o natural como "dado". O sexo existiria antes da inteligibilidade, ou seja, seria pré-dicursivo, anterior à cultura. O caráter imutável, a-histórico e binário do sexo vai impor limites à concepção de gênero e sexualidade. Além disso, ao equacionar a natureza com a heterossexualidade, isto é, com o desejo pelo sexo/gênero oposto, passa-se a supô-la como a forma compulsória de sexualidade.

Ao equacionar a natureza com a heterossexualidade, esta passa a ser institucionalizada como uma norma social, política, jurídica e econômica, de maneira explícita ou implícita. Uma vez institucionalizado e normalizado, a heterossexualidade passa a se manifestar e a ser incorporada na cultura, nas organizações burocráticas, nos discursos e nos sistemas jurídicos (RIOS, 2007).

Qualquer comportamento que fuja desse padrão heterossexual provoca descontinuidade na sequência sexo-gênero-sexualidade e será tratado como questão de minorias e colocado à margem social. De forma paradoxal, "esses sujeitos 'marginalizados' continuam necessários, já que servem para circunscrever os contornos daqueles que são normais e que, de fato, se constituem nos sujeitos que importam" (LOURO, 2004, p. 66).

Em uma lógica binária (masculino versus feminino, homossexual versus heterossexual), sempre existirá e se admitirá um polo que será desvalorizado, designado como minoria que, apesar de ser diferente ou desviante, poderá ser "tolerado" pela sociedade. Nessa lógica, torna-se impossível pensar em múltiplas sexualidades, pois o múltiplo é algo que foge a ela (LOURO, 2004). Para Pocahy (2007), a homofobia e a hierarquização das relações entre homens e mulheres, também denominadas de sexismo, são fruto de uma sexualidade binária que cria um espaço social sexualizado, espaço que atua como sinalizador dos possíveis lugares a serem ocupados.

Ora, a palavra gênero por si só é, em nosso imaginário social, definidora de masculino e feminino e acaba reforçando a concepção binária de sexualidade. Inicialmente, os estudos de gênero estão diretamente relacionados à história das mulheres, e, quando se fala de gênero, fala-se de uma série de aspectos relacionados a mulheres e a questões femininas, considerados opostos aos referentes a homens. Scott (I992) afirma que os estudos de gênero surgiram, na década de I960, com o movimento feminista e tinham um caráter altamente político, daí ser usualmente representado como sinônimo de mulheres. 
Hall (2006) salienta que o feminismo foi um movimento social extremamente importante ao descentrar conceitualmente o sujeito cartesiano e sociológico, e ao questionar a clássica distinção entre dentro e fora, privado e público, trazendo o que é considerado pessoal e privado para o campo político. Para o autor, o movimento feminista abre as portas para a contestação política de novas temáticas, tais como: família, sexualidade, trabalho doméstico, divisão do trabalho, entre outras. Assim, um movimento que iniciou contestando a posição social das mulheres expandiu-se, incluindo questões relacionadas à formação de identidades sexuais e de gênero.

Nesse sentido, Hall (2006, p. I2) atribui ao movimento feminista um papel importante no descentramento do sujeito e da identidade cultural na pós-modernidade, em que o "sujeito previamente vivido como tendo uma identidade unificada e estável, [sic] está se tornando fragmentado; composto não de uma única, mas de várias identidades, algumas vezes contraditórias ou não resolvidas”. Irigaray (I993), ao problematizar o movimento feminista francês, analisa a relação entre sexualidade e discurso e também defende à noção de diferença (descentramento) como uma característica presente na subjetividade humana, enfatizando, em sua obra, a produção da alteridade.

Sarup (I996) defende que as mudanças culturais da sociedade nas duas últimas décadas transformaram-na. Essa transformação é denominada pelo autor de pós-modernidade. Para ele, a sociedade pós-moderna se caracteriza pela aceitação do efêmero, do fragmento e da descontinuidade. No campo científico, Sarup (1996) enfatiza o combate emergente na pós-modernidade às metanarrativas ou metateorias, por meio das quais cada coisa no mundo poderia ser conectada ou representada pela ciência. Para o autor, há uma intensa desconfiança de todos os discursos globais e totalizantes, uma rejeição a metanarrativas, interpretações teóricas de larga escala e de aplicação universal. Ocorre uma condenação

[...] das metanarrativas de Hegel, Marx e Freud como totalizantes. [...] Pós-modernos rejeitam a visão hegeliana de história e a ideia de progresso; na filosofia há uma tendência, associada com o pós-estruturalismo e pós-modernismo, que qualquer projeto universal de emancipação humana é algo suspeito (SARUP, I996, p. 95, tradução nossa).

Lyotard (I986) acredita que, por volta dos anos I950, ocorrem modificações nos estatutos da ciência que culminam com o pós-moderno. Para ele, o fato mais importante dessas mudanças, originadas na crise da ciência e da verdade, não foi apenas a substituição de uma concepção de ciência má por outra. O que ocor- 
reu foi uma mudança na natureza da ciência, provocada principalmente pelas transformações tecnológicas sobre o saber. A ciência se afasta da metafísica com a pós-modernidade, com isso ela também se afasta de conceitos como razão, sujeito autônomo, identidade, totalidade, verdade e progresso: “O pós-moderno, enquanto condição da cultura nesta era caracteriza-se exatamente pela incredulidade perante o metadiscurso filosófico-metafísico, com suas pretensões atemporais e universalizantes" (LYOTARD, I986, p. VIII).

Bauman (200I) salienta que, nesse cenário social, fragmentação e incerteza não são apenas acontecimento momentâneo que estaria conduzindo a passagem da modernidade para a pós-modernidade. Fragmentação e incerteza são os principais traços da pós-modernidade que não são vistos aqui como características ou aspectos meramente transitórios. Da mesma forma que as relações da modernidade estabelecem o que deve ser considerado ciência, a pós-modernidade é um momento de mudanças sociais que provocam mudanças históricas e, consequentemente, o aparecimento de novas formas de pensar e conceber ciência (BAUMAN, I998). Portanto, pode-se afirmar que pós-modernidade é ao mesmo tempo uma nova forma de sociedade (BAUMAN, I998, 200I) que provoca mudanças históricas que acabam constituindo uma nova matriz epistemológica nas ciências (HASSARD, I993).

Entretanto, uma questão fundamental para a pós-modernidade é o sujeito. Na concepção moderna do Humanismo e Iluminismo, o mundo é algo lógico, constituído pela razão e com uma fundamentação universalizante. O discurso reflete a razão e a ordem que já estão prontas "lá fora" no mundo. Para que isso aconteça, há para a modernidade um agente pensante, um sujeito autônomo e consciente dessa ordem exterior (COOPER; BURRELL, 2007). Já o sujeito pósmoderno é visto como algo fragmentado, não autônomo e sem uma identidade. Jameson (1985) afirma que uma das consequências da visão pós-moderna é que não se pode conceber o indivíduo como alienado conforme acredita o marxismo clássico, pois, para o indivíduo ser algo alienado pressupõe-se um senso em que ele é algo coerente em vez de fragmentado. Para Jameson (I985), é somente em termos da existência de um senso centrado de identidade pessoal que a modernidade acredita que indivíduos podem assumir projetos para o futuro ou pensar coerentemente sobre a produção de um futuro significativamente melhor do que o atual. Na pós-modernidade, a alienação do sujeito é substituída pela fragmentação deste.

Um marco contra a concepção biológica de gênero foi o trabalho feminista de Beauvoir (1952) que, em sua obra $O$ segundo sexo, afirma que não se nasce mulher, mas são as práticas exercidas na sociedade que a criam. Contudo, Butler (2003) demonstra que, culturalmente, ainda é o conceito binário, biológico e 
heteronormativo de gênero que atribui existência significável para os indivíduos, tornando-os aptos e qualificados para a vida social. Ao estudar os intersex (pessoas intersex são comumente associadas a hermafroditas, ou seja, pessoas que possuem os dois sexos. Entretanto, de forma mais ampla, são pessoas que têm características que divergem fisicamente dos corpos masculinos e femininos, sendo consideradas indivíduos que apresentam uma condição de não conformidade física com os critérios identitários culturalmente definidos de normalidade), Pino (2007) acaba demonstrando como a normalização compulsória dos corpos e das identidades torna evidente o binarismo homem-mulher, intentando construir e atribuir às identidades sexuais uma coerência necessária entre o corpo sexuado com suas práticas e seus desejos.

Os corpos dos intersex escorregam nas representações socialmente construídas "do que considera como verdadeiramente humano, situando-se nos interstícios entre o que é normal e o que é patológico. Esta 'não-humanidade' ou 'anormalidade' justificará as intervenções médicas com o intuito de adequá-lo ao ideal do dimorfismo sexual", apesar de, na maioria dos casos, a intersexualidade não causar danos à saúde (PINO, 2007, p. I53). Assim, Pino (2007, p. I52) problematiza os conceitos identitários sobre sexo, afirmando que os conceitos proporcionam a "construção do corpo sexuado, seus significados sociais e políticos, assim como sobre o processo de normalização e controle social não apenas dos intersex, mas também de todos os corpos".

Scott (I990) enfatiza que o termo gênero sofre modificação de significado ao ser utilizado pelas feministas americanas com o intuito de questionar as distinções sociais baseadas no sexo biológico. Assim, a palavra gênero passa a ser utilizada para rechaçar o determinismo biológico implícito em termos como sexo. Em sua acepção mais simples, gênero é considerado sinônimo de mulheres, pois gênero soa de forma mais neutra e (a)política do que mulheres. Por fim, a palavra gênero parece ajustar-se como uma terminologia científica das ciências sociais, deixando de ser um termo exclusivamente relacionado à política feminista, passando a designar as relações sociais entre os sexos. Gênero passa a ser uma forma de denotar as construções culturais e papéis sociais relacionados aos homens e mulheres (SCOTT, I990).

Para Scott (I990), é nessa passagem de um conceito biológico para um conceito social que gênero se converte em palavra útil à medida que os estudos sobre o sexo e a sexualidade proliferam. Isso acontece exatamente porque os estudos de gênero oferecem um modo de diferenciar a prática sexual dos papéis sociais destinados a homens e mulheres. O termo gênero acaba colocando um sistema completo de relações que podem incluir o sexo, apesar de não mais estar diretamente determinado pelo sexo, mas que continua como determinante da 
sexualidade. Entretanto, apesar de sua inclusão como elemento social e cultural, o termo gênero ainda continua concebendo e naturalizando a existência de uma visão binária sobre os papéis culturais e sociais. As categorias de análise ainda continuam divididas em dois polos: homem ou mulher.

Similarmente a Scott (I990), Calás e Smircich (I998, p. 276) afirmam que as primeiras teorias feministas tinham como preocupação central as desigualdades entre os sexos, ou seja, "entre duas categorias de pessoas ('masculino' e 'feminino') identificadas por suas características biológicas". Posteriormente ocorreu uma diferenciação entre sexo, que passou a significar biologicamente definido, e gênero que foi (re)significado passando a ser utilizado como algo sociologicamente construído por meio dos processos de socialização. Assim, gênero atingiu um novo significado, afastando-se de um conceito biológico e aproximando-se de uma abordagem sociológica.

Contudo, conforme dito anteriormente, mesmo em sua análise cultural e sociológica, o modelo criado pelo Iluminismo e definido por Laquer (I996) como two-sex-model continua presente nos estudos antropológicos e sociológicos. Existe uma tendência à naturalização e preconcepção da existência de homens e mulheres como categorias essenciais e a-históricas. Assim, propõe-se a substituição, nos estudos organizacionais, do termo gênero por relações sociais de sexo. $\mathrm{O}$ que significa relações sociais de sexo? A resposta a essa pergunta será esclarecida no próximo tópico.

\section{RELAÇÕES SOCIAIS DE SEXO: O FIM DAS ÇATEgorias bINÁRIAS SOBRE A SEXUALIDADE}

Devreux (2005) trabalha com o conceito de relação social de sexo em vez de gênero. Para a autora, a sociologia das relações sociais de sexo se diferencia das teorias de gênero. E a principal diferença está no fato de que gênero fala mais de categorias do que na "acentuação do fato de que as relações entre os homens e as mulheres constituem uma relação social” (DEVREUX, 2005, p. 562). Para a autora, o gênero diz mais das categorias, da categorização do sexo que, na realidade, é o produto da relação, ou seja, uma das modalidades pelas quais a relação social entre os sexos se manifesta, mas que não se refere a toda relação (DEVREUX, 2005, p. 562): 
No sentido marxista, uma relação social é uma oposição estrutural de duas classes com interesses antagônicos. Com o estudo das relações sociais de sexo assistimos a um enriquecimento do marxismo. Para esse campo de estudos, os sistemas de representação [...] são tão importantes quanto às práticas de divisão do trabalho e do poder, tão importantes quanto a dimensão material na dominação dos homens sobre as mulheres. Reciprocamente, o material é tão importante quanto o ideal, o que rompe com a concepção exposta por Pierre Bourdieu sobre a dominação masculina [...]. Para ele, no caso de dominação masculina, as formas simbólicas da dominação são preeminentes. A opressão material é admitida, mas deixada fora da análise. Pierre Bourdieu fez das formas simbólicas da dominação a totalidade heurística da dominação masculina.

Outro motivo pelo qual Devreux (2005) evita o uso do conceito de gênero é que ela se baseia na explicitação do sexo. Nesse sentido, prefere utilizar o conceito de relação social de sexo. A autora prefere o conceito de relação social de sexo ao de gênero pelo fato de que, no idioma francês, a palavra gênero é polissêmica, possui uma definição vaga, incerta do conceito e, algumas vezes, é utilizada como sexo do registro de nascimento, às vezes, é o gênero gramatical e, outras vezes, a categorização social.

Assim, para Devreux (2005), a utilização do conceito de gênero possibilitou que as pesquisadoras francesas fossem vistas como menos agressivas por suas instituições e seus colegas homens. Entretanto, baseando-se na dialética marxista, Devreux (2005, p. 564) acredita que a "relação social de sexo nomeia explicitamente a confrontação entre duas classes de sexo. Não pode haver relação social com uma categoria única. Não pode haver relação social sem confrontação”.

As atividades das relações sociais de sexo têm propriedades formais representadas por relações sistêmicas. As primeiras propriedades formais são a divisão sexual do trabalho, a divisão sexual do poder e a categorização do sexo. As segundas são as características formais sob as quais essas relações aparecem no espaço social compartilhado em esferas ou campos do trabalho produtivo, da família, da escola, do político, entre outros, ou seja, trata-se da transversalidade e do antagonismo das relações sociais de sexo (DEVREUX, 2005).

Devreux (2005) acredita que a divisão sexual do trabalho, a divisão sexual do poder e a categorização do sexo podem ser vistas como três atividades e três expressões das relações sociais de sexo. Entretanto, não se pode afirmar que existe entre essas atividades uma procedência de alguma delas sobre as demais, pois "as relações sociais de sexo exprimem-se simultânea e conjuntamente por essas três modalidades” (DEVREUX, 2005, p. 567). 
A divisão sexual do poder é, para Devreux (2005), algo transversal por integrar a relação social de sexo com a divisão sexual do trabalho. Segundo a autora, a repartição dos poderes entre os sexos não ocorre por processos naturais relacionados às capacidades físicas entre homens e mulheres. A divisão do poder apoia-se sobre a divisão sexual do trabalho, na qual os homens fundam a divisão do poder na repartição das funções produtivas que ocorrem no ambiente de trabalho, bem como nas funções reprodutivas exercidas no âmbito familiar.

Entretanto, Devreux (2005) afirma que a divisão do poder se apoia também na categorização, ou seja, na definição de categorias relacionadas à sexuação social. A categorização seria exercida por meio de um conjunto de fatores que se associam à divisão sexual do poder e do trabalho. Na categorização, há uma invenção, criação e reafirmação de categorias sexuadas.

A primeira das grandes categorizações sociais de sexo concerne, evidentemente, à partição dos indivíduos entre categorias de sexo entre "homens" e "mulheres". Seguiu-se toda uma visão do mundo organizada em um sistema de atributos, de normas, de valores, etc., fixando uma oposição entre o "masculino" e o "feminino" (DEVREUX, 2005, p. 568).

Torrão Filho (2004), em concordância com Devreux (2005), salienta que a diferenciação entre os sexos cria categorias que já predeterminam a identidade do masculino e do feminino. Nesse processo, não apenas as mulheres aprendem a manter a feminilidade, mas também os homens são, a todo o momento, vigiados para manter sua masculinidade. Apesar de um afastamento do biológico para explicar as diferenças entre sexos, atribuindo-lhes caráter social, cultural e histórico, o pensamento de Devreux (2005) ainda está pautado na divisão do mundo entre masculino e feminino, pois o que a autora questiona é o status e as consequências dessa categorização, que tende a dar uma posição de destaque ao masculino em detrimento do feminino, e não à inexistência dessas categorias dicotômicas e excludentes. A autora, em seu conceito sobre relações sociais de sexo, acaba enfatizando uma visão dialética, salientando a luta entre essas duas categorias e evidenciando a construção dessas categorias por meio de relações de poder.

Apesar de os autores deste artigo terem estudado a obra de Devreux (2005) e defenderem que o termo gênero deve ser substituído nos estudos que envolvem sexualidade nas organizações por relações sociais de sexo, eles não defendem a utilização da expressão relações sociais de sexo com o mesmo significado empregado por Devreux (2005). Ao definirmos o significado de relações sociais de sexo, gostaríamos de esclarecer alguns aspectos sobre o conceito. Contudo, para entender 
como esse conceito é utilizado aqui, algumas questões devem ser respondidas, entre elas destacam-se: o conceito de relações sociais de sexo utilizado pelos autores deste artigo é semelhando ao de Devreux (2005)? Se não, o que o diferencia? Qual é a possível relação entre o conceito de relações sociais de sexo defendido por Devreux (2005) e a analítica queer?

Para responder a esses questionamentos, é necessário esclarecer que o conceito de relações sociais de sexo utilizado neste artigo não é fundamentado no marxismo de Devreux (2005), mas no pós-estruturalismo de Foucault (I984, I985, I988). Vale ressaltar que, tanto para Foucault (I984, I985, I988) como para Devreux (2005), a sexualidade é histórica, cultural e socialmente construída. A principal divergência entre o marxismo de Devreux (2005) e o pós-estruturalismo de Foucault (I984, I985, I988) é que, para este, categorias como masculino e feminino também são frutos de relações de poder e não existem a priori como Devreux (2005) acredita. Ou seja, o que se enfatiza não é apenas que masculino e feminino são construídos por relações de poder historicamente fundamentadas, mas também que essas categorias não são naturais nem existem a priori. Masculino e feminino são categorias historicamente criadas para estabelecer relações de poder em um contexto histórico específico, ocorrido no século XVII, conforme já explicado, e não levam em consideração toda a diversidade e heterogeneidade da sexualidade humana. O conceito de relações sociais de sexo empregado pelos autores deste artigo tem o objetivo de denunciar e desconstruir a existência a priori dessas duas categorias por meio da problematizando das relações de poder que atuam como dispositivos de controle sobre a sexualidade.

Somente entendida sobre um enfoque pós-estruturalista é que as relações sociais de sexo podem ser utilizadas como substituto da palavra gênero ao trabalharmos com a analítica queer para estudar as relações de poder que envolvem a sexualidade no espaço organizacional. Nesse sentido, a analítica queer emerge exatamente diante da problematização dessas categorias. Mas o que significa analítica queer? Qual é o seu intento? O que propõe? As respostas a essas perguntas serão esclarecidas no próximo tópico.

\section{A ANALÍTICA QUEER}

Para Foucault (I988), a sexualidade só pode ser analisada sob um dispositivo historicamente construído. Foucault (I988, p. 80) acredita que, quando se estuda a sexualidade, o que está em jogo é dirigir-se "menos para uma 'teoria' do que para uma 'analítica' do poder". Infere-se que a sexualidade é constituída por relações de poder que fazem parte de um jogo da verdade sobre a própria sexua- 
lidade. Entretanto, não há uma verdade ou essência em relação à sexualidade. O que existem são dispositivos que produzem todo um discurso sobre a sexualidade, discurso que estabelece toda uma regra de conduta. Em outras palavras, para estudar a sexualidade, faz-se necessário entender o dispositivo da sexualidade de determinada época histórica. Dispositivo da sexualidade é definido por Foucault (I988, p. 82) da seguinte forma:

O poder sobre o sexo se exerceria do mesmo modo a todos os níveis. De alto a baixo, em suas decisões globais como em suas intervenções capilares, não importando os aparelhos ou instituições em que apóie, agiria de maneira uniforme e maciça; funcionaria de acordo com as engrenagens simples e infinitamente reproduzidas da lei, da interdição e da censura: do Estado à família, do príncipe ao pai, do tribunal à quinquilharia das punições quotidianas, das instâncias da dominação social às estruturas constitutivas do próprio sujeito, encontrar-se-ia, em escalas diferentes apenas, uma forma geral de poder.

O pensamento queer adquire força com os questionamentos do pós-estruturalismo francês. Lara Neto (2007) esclarece que a base do pensamento queer está na analítica de poder de Foucault, salientando que Foucault foi pioneiro ao descartar o binômio sexo/natureza, passando a abordar o sexo em termos de história, significação e discurso. Miskolci (2007) afirma que, em termos metodológicos e teóricos, a abordagem queer surge do encontro entre os estudos culturais norte-americanos com o pós-estruturalismo francês. Para o autor, esse encontro permitiu a problematização de concepções clássicas de sujeito e identidade. Para Miskolci (2007), a afirmação foucaultiana de que a sexualidade tornou-se um dispositivo histórico de poder desenvolvido pelas sociedades ocidentais modernas a partir do século XVIII com o intuito de inserir o sexo em sistemas de utilidade e regulação social é o ponto de partida do pensamento queer.

Pino (2007) aponta que os estudos queer emergem na década de I980 como uma corrente de pensamento que questiona as formas correntes de entender as identidades sociais. Sua efervescência vem dos estudos gays e lésbicos, bem como da teoria feminista, da sociologia do desvio norte-americana e do pós-estruturalismo francês. Os precursores da analítica queer são Michel Foucault, Joan Scott e Gayle Rubin (PINO, 2007). Para Pino (2007), os teóricos Eve Kosofsky Sedgwick, Teresa de Lauretis, David Halperin, Judith Butler, Steve Seidman, Michael Warner, Beatriz Preciado e Judith Halberstan são legítimos representantes da analítica queer. Louro (2008) afirma que o pensamento queer entra definitivamente em cena com a publicação em I986 de um artigo da historiadora americana Joan Scott, intitulado "Gender: a useful category of historical analysis". Nesse artigo, 
Scott não esconde que pegou emprestado conceitos pós-estruturalistas de Michel Foucault e Jacques Derrida para desenvolver o pensamento queer. Miskolci (2007) também defende que, além de Foucault, Jacques Derrida (2004), por meio de seu método desconstrutivo, exerceu forte influência no pensamento queer, salientando que foi Teresa de Lauretis, em I990, que utilizou pela primeira vez a denominação teoria queer. Nos estudos organizacionais brasileiros, ressaltam-se os trabalhos de Irigaray $(2007 \mathrm{a}, 2007 \mathrm{~b}, 2008)$ como precursores da utilização da teoria queer no campo organizacional.

Diferentemente dos autores descritos, acreditamos que o pensamento queer não é uma teoria, apesar de os estudiosos a denominarem dessa forma. Não é uma teoria, pois o pós-estruturalismo foucaultiano, que deu a base epistemológica e as principais fundamentações para a analítica queer, nunca intentou ser ou construir teorias, nem metanarrativas. Como o pensamento queer é apenas uma forma de analisar a sexualidade sem cair nas armadilhas construídas pelas relações de poder que produzem uma visão binária e identitária sobre a sexualidade, o principal alvo é o estudo das relações de poder que envolvem o dispositivo da sexualidade sob uma perspectiva foucaultiana de análise. Dessa forma, seria incoerente nominá-lo de teoria, pois Foucault não desenvolve uma teoria sobre o poder, mas sim uma analítica. Com base nessas considerações, os autores deste trabalho preferem utilizar o termo "pensamento queer" ou "analítica queer" em vez de "teoria queer". Após esses esclarecimentos, uma questão se faz necessária: o que realmente diferencia a analítica queer dos estudos culturais e sociológicos sobre gênero? Em resposta a essa questão, pode-se afirmar que a analítica queer se diferencia das demais em quatro aspectos: a) crítica ao modelo sexual binário, seja ele biológico ou sociológico/cultural; b) fim das classificações em identidades sexuais, princípio que a fundamenta; c) combate à heteronormatividade; e d) desnaturalização do sexo. Esses aspectos não estão dissociados, bem como não há uma hierarquia entre eles.

Em razão de toda a diversidade no campo da sexualidade e de uma tentativa de quebrar com categorias binárias de classificação e normalização do comportamento sexual, é que se cunhou o termo queer. Antes de ser um conceito filosófico, queer já era uma gíria utilizada pela população dos Estados Unidos quando se referia a homossexuais ou bissexuais. Em relação a isso, Swain (200I, p. 92) afirma que "Queer em um primeiro momento, foi o nome dados aos homossexuais, os 'bizarros'; em seguida, um novo fenômeno se introduz no discurso e a prática correspondente se revela, tomando para si esta denominação: o bissexualismo".

Entretanto, o termo queer é um conceito filosófico pós-estruturalista e se desprende de seu uso coloquial. Queer como conceito filosófico descola-se do significado quando empregado como gíria norte-americana, ou seja, para o pós-estrutu- 
ralismo queer não significa que as pessoas sejam homossexuais ou bissexuais. $\mathrm{O}$ pensamento queer emerge com uma preocupação de que é preciso desconstruir o caráter permanente da oposição binária masculino-feminino. Para Scott (I990), é recorrente nos estudos e na compreensão das sociedades uma análise dicotômica sobre gêneros, na qual homem e mulher são concebidos como polos opostos, tendendo a marcar uma superioridade do homem sobre a mulher. Aliás, a dicotomia (teoria/prática, ciência/ideologia, presença/ausência, homossexual/ heterossexual etc.) é uma das marcas da modernidade (LOURO, 2008).

O pensamento queer entende que desconstruir a polaridade rígida dos gêneros significa "problematizar tanto a oposição entre eles quanto a unidade interna de cada um” (LOURO, 2008, p. 3I-32). Para o pensamento queer, o polo masculino também contém o feminino, mesmo que seja de forma postergada e reprimida, e vice-versa. Mas também implica "perceber que cada um desses pólos é internamente fragmentado e dividido (afinal não existe a mulher, mas várias e diferentes mulheres que não são idênticas entre si, que podem ou não ser solidárias, cúmplices ou opositoras)" (LOURO, 2008, p. 32). Além de desconstruir o binarismo entre homem-mulher, uma

[...] das conseqüências mais significativas da desconstrução dessa oposição binária reside na possibilidade que abre para que se compreendam e incluam as diferentes formas de masculinidade e feminilidade que se constituem socialmente. A concepção dos gêneros como se produzindo dentro de uma lógica dicotômica implica um pólo que se contrapõe a outro (portanto uma idéia singular de masculinidade e de feminilidade), e isso supõe ignorar ou negar todos os sujeitos sociais que não se "enquadram" em uma dessas formas. Romper a dicotomia poderá abalar o enraizado caráter heterossexual que estaria na visão de muitos/ as, presente no conceito "gênero". Na verdade penso que o conceito só poderá manter sua utilidade teórica na medida em que incorporar esses questionamentos. Mulheres e homens que vivem feminilidades e masculinidades de formas diversas das hegemônicas e que, portanto, muitas vezes não são representados/ as ou reconhecidos/as como "verdadeiras/verdadeiros" mulheres e homens, fazem críticas a esta estrita e estreita concepção binária (LOURO, 2008, p. 34).

Swain (200I) afirma que o discurso sobre o real tende a mascarar a diversidade e multiplicidade que habitam o campo sexual, tentando transformar essa diversidade em um perfil unívoco e, em consequência, cristalizando identidades em torno do eixo traçado pelo sexo biológico, considerado natural e definidor de corpos e papéis sociais. Para Swain (200I, p. I), o "sexo se desdobra em sexualidade normatizada, a heterossexualidade, cujo caráter reprodutivo confere-lhe 
o selo de normalidade". Essa autora salienta que sob uma ótica queer o mais importante é sacudir um mundo marcado por certezas do que buscar respostas. O que um pesquisador queer deve fazer é problematizar aquilo que se apresenta como natural, estável e verdade. Para Swain (200I, p. I), devem-se sacudir "as verdades que nos definem e limitam, [pois, assim] revela-se um caminho para o desvelamento de uma realidade múltipla".

O que Swain (200I) está realmente problematizando é exatamente a ideia de identidade sexual, e nesse sentido o "termo queer tem sido empregado como um marcador da instabilidade da identidade ao mesmo tempo em que busca dar conta de todos os outsiders do sexo e do gênero" (LARA NETO, 2007, p. 5). Diante disso, para Louro (2004, p. 28), o grande desafio não é somente assumir que posições relacionadas a gênero e à sexualidade se multipliquem e que, em razão disso, seja impossível lidar com elas baseando-se em esquemas binários: "O grande desafio é admitir que as fronteiras vêm sendo constantemente atravessadas e - o que é ainda mais complicado - que o lugar social no qual alguns sujeitos vivem é exatamente a fronteira".

O pensamento queer quer exatamente quebrar essa reclassificação, defendendo uma política pós-identitária no campo da sexualidade. A sexualidade como fruto de práticas discursivas, conforme demonstrado por Foucault (I984, I985, I988), vai ser um grande catalisador do pensamento queer. Louro (2004) adverte que a desconstrução de um discurso binário contido no pensamento queer manifesta a interdependência e a fragmentação do masculino e do feminino. O masculino contém o feminino e vice-versa, mesmo que esse conter ocorra de forma desviada ou negada, ou seja, cada polo carrega vestígios do outro e há uma interdependência entre eles, para que adquiram sentido. Entretanto, isso não é sinônimo de unicidade, pois cada polo é, em si mesmo, algo fragmentado e plural:

[...] queer significa colocar-se contra a normalização - venha ela de onde vier. Seu alvo mais imediato de oposição é, certamente, a heteronormatividade compulsória da sociedade; mas não escaparia de sua crítica a normalização e a estabilidade propostas pela política de identidade [...]. Queer representa claramente a diferença que não quer ser assimilada ou tolerada, e, portanto sua forma de ação é muito mais transgressiva e perturbadora (LOURO, 2004, p. 38-39).

Por fim, além de defender uma política pós-identitária, a analítica queer quer desnaturalizar a heteronormatividade. Para Pino (2007), a heterossexualidade compulsória atua obrigando socialmente as pessoas a se relacionar, amorosa e 
sexualmente, com pessoas do sexo oposto. Já a heteronormatividade age no sentido de enquadrar todas as relações, mesmo aquelas inaceitáveis entre pessoas do mesmo sexo, em um binarismo de gênero que pretende organizar as práticas, os atos e desejos, fundamentando-se o modelo do casal heterossexual reprodutivo e seguindo-o. A analítica queer combate a heteronormatividade, denunciando seu pressuposto de heterossexualidade como natural e fundamental para a vida em sociedade (MISKOLCI, 2007).

\section{CONCLUSÃO}

Este trabalho buscou discutir uma abordagem crítica ainda não muito trabalhada nos estudos organizacionais brasileiros, que aqui foi denominada de analítica queer. Essa escolha se deu para quebrar a ideia de gêneros e a naturalização binária entre masculino e feminino. Acredita-se que estudando as relações sociais de sexo por meio da analítica queer se poderá observar que a vida, em todas as suas dimensões, é algo muito mais múltiplo do que se concebe. Intentase desconstruir e problematizar categorias e classificações identitárias binárias relacionadas à sexualidade, tais como masculino versus feminino, homossexual versus heterossexual, dentre outras, denunciando as relações de poder presentes nessas categorizações. Por exemplo, classificar pessoas que tenham traços efeminados como homossexuais parece ser um grande erro. Em outras palavras, esse tipo de classificação e rotulação torna-se completamente desnecessário. Definir o homossexual ou a mulher como uma pessoa efeminada não passa de uma tentativa de criar fronteiras e, consequentemente, uma identidade que estabeleceriam o comportamento e as características que marcam o homossexual e a mulher. O desejo é algo vivo, e, por mais que a sociedade crie regras sociais e morais que tentem interditar qualquer forma de desejo, este sempre escapa ao controle e manifesta-se sob diversas formas.

Com base no exposto, alinhado com o pensamento queer e com o pós-estruturalismo, pode-se afirmar que dividir a vida em duas categorias de comportamento sexual, oferecendo às pessoas apenas duas alternativas de exercício sexual, tentando classificá-las como homossexual ou hétero por meio de um gabarito previamente estabelecido no século XVIII, não manifesta o que realmente acontece na vida real contemporânea. Somos diversas coisas concomitantemente, diversos desejos, diversas pulsões. Em nosso dia a dia, ainda reproduzimos um discurso identitário e binário (homo/hétero, mulher/homem), apesar de toda a diversidade e práticas sexuais existentes. Qual seria o motivo da construção de uma realidade discursiva desconectada com as práticas do mundo real? 
Ao tratarmos as relações sociais de sexo apenas como algo binário (homossexual/heterossexual, homem/mulher, masculino/feminino), acabamos reforçando os dispositivos de poder, relacionados à sexualidade, dispositivos esses que a analítica queer intenta denunciar e combater. A naturalização do modelo binário e identitário é uma estratégia que permite a manutenção de velhas práticas de controle, só que com uma nova roupagem. Funciona como um biopoder conforme descrito por Foucault (I999). O binarismo identitário proporciona a divisão sexual do trabalho, faz que os sistemas econômicos, sociais e de gênero interajam de modo não causal, opera simultaneamente com as estruturas socioeconômicas hegemônicas (SCOTT, I990) e produz a sensação de que o poder é algo unificado e coerente.

Portanto, para atingir o significado de relações sociais de sexo e o desenvolvimento de políticas emancipatórias nas organizações, é preciso considerar tanto os sujeitos individuais como a organização social, analisar a natureza de suas (inter)relações e substituir a noção de que o poder é algo coerente e unificado e se encontra centralizado nas estruturas organizacionais. As relações sociais de sexo são o campo primário no qual e por meio do qual se articula o poder, mas não é o único campo. Tal fato pode ser constatado pela utilização do conceito binário/identitário de gênero de maneira persistente e recorrente para facilitar a significação social do poder nas tradições ocidentais, judaico-cristãs e islâmicas (SCOTT, I990).

Em relação aos homossexuais, ressalta-se que a classificação em minorias é uma busca de características que sejam comuns e que possibilitem encontrar uma identidade homossexual. Swain (200I) afirma que a busca de identidade é uma característica da modernidade e que toda identidade é um mecanismo de inclusão/exclusão que opera de forma conjunta. A identidade é uma relação de poder em que as significações hegemônicas acabam excluindo as não hegemônicas. Ao se estabelecer a diferença entre duas identidades, tende-se a incluir e valorizar o que é considerado hegemônico e a desvalorizar e excluir aquilo que é minoria com o principal intuito de preservar a harmonia social e evitar o conflito. A classificação de homossexuais em minorias não garante a igualdade, mas serve como um dispositivo de controle e hierarquização social.

De forma contrária, ao trabalhar com o pós-estruturalismo francês, este artigo se diferencia e se afasta dessa lógica, exatamente por entender que tratar os homossexuais, como também mulheres, negros, portadores de necessidades especiais, entre outros, como minoria é constituir identidades. Acredita-se que criar identidades e salientar as diferenças entre essas identidades é um dispositivo de poder que cria um círculo vicioso no qual se reconstrói e se reafirma aquilo que se quer banir: a discriminação. A concepção de uma sexualidade múl- 
tipla e heterogênea abre a possibilidade de que todos os homens se vejam como semelhantes em suas diversidades, sejam quais forem essas diversidades, e não apenas como diferentes em razão de suas identidades. Somente assim, na semelhança pela diversidade, que a discriminação, seja ela relacionada à sexualidade ou a outra forma, poderá ser combatida.

Para Rolnik (I989), a produção do desejo é produção de realidade, sendo indissociável e ao mesmo tempo material, semiótica e social. Para Rolnik (1989, p. 56), o desejo é uma produção social responsável pela criação e pelo desmanche de mundos: "Fomos entendendo que o desejo não corresponde a um suposto campo individual ou interindividual, o qual estaria numa relação de exterioridade ao campo social". Em outras palavras, não existe sociedade que não seja constituída por investimentos de desejo em determinada direção, "com esta ou aquela estratégia e, reciprocamente, não existem investimentos de desejo que não sejam os próprios movimentos de atualização de um certo tipo de prática e discurso, ou seja, atualização de um certo tipo de sociedade" (ROLNIK, I989, p. 58 , grifo da autora).

Em razão disso, estudar gênero e denunciar seus dispositivos de poder envolvidos com a sexualidade não é uma tarefa secundária, mas sim primordial caso se queira mudar as diversas práticas organizacionais, inclusive as que são vistas como independentes de questões de gênero.

Por fim, acredita-se que o uso da analítica queer tem muito a contribuir para os estudos organizacionais, por enfatizar aspectos locais e emergentes na análise organizacional focados no estudo das relações sociais de sexo, salientando, assim, toda a diversidade e heterogeneidade em relação à sexualidade dos membros de determinada empresa. Além disso, demonstra, problematiza, desconstrói e denuncia as relações de poder estabelecidas nos espaços laborais fundamentadas no dispositivo da sexualidade, trazendo para os estudos organizacionais novas maneiras de estudar e entender os fenômenos organizacionais sob uma perspectiva crítica.

\section{REFERÊNCIAS}

ALVESSON, M.; DEETZ, S. Teoria crítica e abordagens pós-modernas para estudos organizacionais. In: CLEGG, S. R.; HARDY, C.; NORD, W. R. Handbook de estudos organizacionais. São Paulo: Atlas, I998. v. I.

ALVESSON, M.; WILLMOTT, H. Making sense of management. London: Sage, I996.

BAUMAN, Z. O mal-estar da pós-modernidade. Rio de Janeiro: Jorge Zahar, I998. Modernidade líquida. Rio de Janeiro: Jorge Zahar, 200I.

BEAUVOIR, S. Le deuxième sexe. Paris: Gallimard, I952.

BUTLER, J. Problemas de gênero: feminismo e subversão da identidade. Rio de Janeiro: Civilização Brasileira, 2003. 
CALÁS, M. B.; SMIRCICH, L. Do ponto de vista da mulher: abordagens feministas em estudos organizacionais. In: CLEGG, S. R.; HARDY, C.; NORD, W. R. Handbook de estudos organizacionais. São Paulo: Atlas, I998. v. I.

COOPER, R.; BURRELL, G. Modernismo, pós-modernismo e análise organizacional: uma introdução. In: CALDAS, M. P.; BERTERO, C. O. (Coord.). Teoria das organizações. São Paulo: Atlas, 2007.

COSTA, J. F. A face e o verso: estudos sobre o homoerotismo II. São Paulo: Escuta, I995.

DE LAURETIS, T. Technologies of gender, essays on theory, film and fiction. Bloomington: Indiana University Press, I987.

DERRIDA, J. Gramatologia. São Paulo: Perspectiva, 2004 .

DEVREUX, A. M. A teoria das relações sociais de sexo: um quadro de análise sobre a dominação masculina. Sociedade e Estado, Brasília, v. 20, n. 3, p. 56I-584, 2005.

FOUCAULT, M. História da sexualidade II: o uso dos prazeres. Rio de Janeiro: Edições Graal, I984. História da sexualidade III: o cuidado de si. Rio de Janeiro: Edições Graal, I985. História da sexualidade I: a vontade de saber. Rio de Janeiro: Edições Graal, I988. Em defesa da sociedade. São Paulo: Martins Fontes, I999.

FOURNIER, V.; GREY, C. Hora da verdade: condições e prospectos para os estudos críticos de gestão. In: CALDAS, M. P.; BERTERO, C. O. (Coord.). Teoria das organizações. São Paulo: Atlas, 2007. HALL, S. A identidade cultural na pós-modernidade. Rio de Janeiro: DP\&A, 2006.

HASSARD, J. Sociology and organization theory. New York: Cambridge University Press, I993.

HEIBORN. M. L. Gênero: um olhar estruturalista. In: PEDRO, J. M.; GROSSI, M. P. Masculino, feminino, plural. Florianópolis: Mulheres, 1998.

IRIGARAY, H. A. Políticas de diversidade nas organizações: uma questão de discurso? In: ENCONTRO NACIONAL DOS PROGRAMAS DE PÓS-GRADUAÇÃO EM ADMINISTRAÇÃO, 3I., 2007, Rio de Janeiro. Anais... Rio de Janeiro: Enanpad, 2007 a.

Estratégia de sobrevivência dos gays no ambiente de trabalho. In: ENCONTRO NACIONAL DOS PROGRAMAS DE PÓS-GRADUAÇÃO EM ADMINISTRAÇÃO, 3I., 2007, Rio de Janeiro. Anais... Rio de Janeiro: Enanpad, 2007b.

Discriminação por orientação sexual no ambiente de trabalho: uma questão de classe social? Uma análise sob a ótica da pós-modernidade crítica e da Queer Theory. In: ENCONTRO NACIONAL DE ADMINISTRAÇÃO PÚBLICA E GOVERNANÇA, 2008, Salvador. Anais... Salvador: Enapg, 2008.

IRIGARAY, L. An ethics of sexual difference. London: Athlone, I993.

JAMESON, F. Postmodernism, or the cultural logic of late capitalism. London: Plutuo, I985.

LAQUEUR, T. Inventando o sexo: corpo e gênero dos gregos a Freud. Rio de Janeiro: Relume Dumará, I996.

LARA NETO, O. A. A teoria queer e as sexualidades no contexto brasileiro: desafios teórico-metodológicos. In: ENCONTRO ANUAL DA ANPOCS, 3I., 2007, Caxambu. Anais... Minas Gerais, 2007. LOURO, G. L. Um corpo estranho: ensaios sobre sexualidade e teoria queer. Belo Horizonte: Autêntica, 2004 .

Gênero, sexualidade e educação: uma perspectiva pós-estruturalista. Petrópolis: Vozes, 2008.

LYOTARD, J-F. O pós-moderno. Rio de Janeiro: José Olympio, I986. 
MISKOLCI, R. A teoria queer e a questão das diferenças: por uma analítica da normalilzação. In: CONGRESSO DE LEITURA DO BRASIL, I6., 2007, Campinas. Anais... Campinas: Unicamp, 2007.

NARDI, H. C. Nas tramas do humano: quando a sexualidade interdita o trabalho. In: POCAHY, F. Rompendo o silêncio: homofobia e heterossexismo na sociedade contemporânea. Políticas, teoria e atuação. Porto Alegre: Nuances, 2007.

PINO, N. P. A teoria queer e os intersex: experiências invisíveis de corpos des-feitos. Cadernos Pagu, v. 28 , p. I49-I74, jan./jun. 2007.

POCAHY, F. Um mundo de injúrias e outras violações. Reflexões sobre a violência heterossexual e homofóbica a partir da experiência do CRDH rompa o silêncio. In: POCAHY, F. Rompendo o silêncio: homofobia e heterossexismo na sociedade contemporânea. Políticas, teoria e atuação. Porto Alegre: Nuances, 2007.

RAGO, M. Epistemologia feminista, gênero e história. In: PEDRO, J. M.; GROSSI, M. P. Masculino, feminino, plural. Florianópolis: Mulheres, 1998.

RIOS, R. R. O conceito de homofobia na perspectiva dos direitos humanos e no contexto dos estudos sobre preconceito e discriminação. In: POCAHY, F. Rompendo o silêncio: homofobia e heterossexismo na sociedade contemporânea. Políticas, teoria e atuação. Porto Alegre: Nuances, 2007. ROLNIK, S. Cartografia sentimental: transformações contemporâneas do desejo. São Paulo: Estação Liberdade, I989.

SARUP, M. Identity, culture and the postmodern world. Georgia: The University of Georgia Press, I996.

SCOTT, J. Gênero: uma categoria útil de análise histórica. Educação e Realidade, Porto Alegre, v. I6, n. 2, p. 5-22, jul./dez. I990.

História das mulheres. In: BURKE, P. A escrita da história: novas perspectivas. São Paulo: Editora Unesp, I992.

SWAIN, T. N. Para além do binário: os queers e o heterogêneo. Gênero, Niterói, v. 2, n. I, p. 87-98, 2. sem. 200I.

TORRÃO FILHO, A. Uma questão de gênero: onde o masculino e o feminino se cruzam. Cadernos Pagu, Campinas, 24, p. I27-I52, 2004.

VIEIRA, M. M. F.; CALDAS, M. P. Teoria crítica e pós-modernismo: principais alternativas à hegemonia funcionalista. In: CALDAS, M. P.; BERTERO, C. O. (Coord.). Teoria das organizações. São Paulo: Atlas, 2007. 